\title{
Associations between lifestyle factors and breast cancer in healthy women and breast cancer survivors and need for ehealth support
}

\author{
Simone Doreleijers \\ Maastricht University \\ s.doreleijers@student.maastrichtuniversity.nl
}

\begin{abstract}
Breast cancer is the leading cause of cancer-related mortality amongst women and its' incidence is highest in Western-Europe. Contributing factors are higher levels of obesity and alcohol consumption, and lower levels of physical activity. Literature suggests a poor compliance to health recommendations in both breast cancer survivors and women without history of breast cancer. In the light of breast cancer prevention it is of great importance to improve this adherence and to integrate health education. Ehealth counselling might be a useful medium to obtain this goal. To gain an insight in women's needs and requirements regarding an eHealth programme, this study used a qualitative research design based on the iChange Model.
\end{abstract}

Keywords

Breast cancer, lifestyle factors, tailored eHealth counselling, iChange Model

\section{Introduction}

Breast cancer is the leading cause of cancer-related mortality amongst women and its' incidence is highest in Western-Europe (1). Contributing factors are higher levels of obesity and alcohol consumption, and lower levels of physical activity (1). Not only do these lifestyle factors increase the risk of breast cancer onset, they also lead to higher cancer related mortality and to a higher risk of cancer recurrence (2-6). Therefore, focussing on these lifestyle behaviours is highly relevant for both women in the general population and breast cancer survivors. Nonetheless, literature suggests a low prevalence of meeting health recommendations in both groups $(7,8)$. In order for these numbers to improve, efforts to integrate health education are thus crucial. Ehealth could be a useful medium 
for trials with such counselling have proven to be effective in optimizing health behaviours and health self-efficacy (9-11).

In order to implement ehealth counselling as either a breast cancer prevention mean or as a personalised care service, it is highly important to gain insight in the level of awareness of the importance of lifestyle factors amongst women with and without history of breast cancer. Moreover, developing a better understanding concerning women's needs and requirements regarding an ehealth programme is needed. Therefore, individual interviews based on the ichange model were conducted (12). This model is based on the reasoning that one's behaviours are determined by one's motivation, intention and abilities. Foremost, motivation exists of attitude, social influences and self-efficacy. Attitude could be described as the unity of perceived advantages and disadvantages of a behavioural change. Social influences cover social support, social modelling and one's perceptions of the behaviour of a social model (social norms). One's expected capability of carrying out a behavioural change could be depicted as one's self-efficacy. When one's intentions are concerned, they represent the level to which one is willing to contemplate a behavioural change and at what pace one is willing to do so. Lastly, behaviour is determined by one's abilities to achieve a behavioural change through adequate planning and the exertion of these plans (13).

This study has two objectives. the first objective is to explore the awareness of women with and without history of breast cancer when it comes to the relationship between a healthy lifestyle and the risk of breast cancer (recurrence). the second objective of the study is to obtain a better understanding of women's needs and requirements regarding an ehealth counselling programme.

\section{Material and methods}

\section{Recruitment and participants}

The participants consisted of two groups: women without history of breast cancer $(n=10)$ and breast cancer survivors $(n=10)$. Both groups were convenience samples, meaning that participants were selected based on their proximity or accessibility to the researcher.

\section{Procedure}

Before the interviews took place, all participants received an information letter and an informed consent (IC), which they were asked to sign before participating in the project. The information letter contained information about the research project and notified the 
participant of the interview subjects. By signing, participants gave permission for the interview to be recorded. Interviews were conducted at the homes of participants and were all taken by the same researcher.

The research project was based on a deductive qualitative research design and conversations were semi-structured with set question routes based on the iChange Model. Main themes that were addressed in each dialogue were previous experience with breast cancer prevention counselling, behaviour (current lifestyle), awareness factors, attitude, social influences and self-efficacy.

\section{Data analysis}

Based on the questions and the given answers, a thematic coding tree consistent of themes and subthemes was conducted for each sample. The data was first analyzed manually and subsequently using Nvivo 10 (www.nvivo.nl), in which significant passages were marked.

\section{Results}

\section{Characteristics of the samples}

When the characteristics of both samples were compared, it was conspicuous that the mean age of the women without history of breast cancer was 7.7 years younger than the mean age of the breast cancer survivors (Table 1). Both samples contained very few women with a low education level and in both samples a previous experience with breast cancer prevention counselling was rare. The same applied for familiarity with eHealth. However, women without history of breast cancer had heard of eHealth more often than breast cancer survivors. On the contrary, breast cancer survivors were more frequently healthy and more often aware of (part of) the lifestyle-related risk factors than women without history of breast cancer. Many breast cancer survivors stated that despite the lack of counselling on breast cancer prevention, they had done their own research on the internet.

Comparison between attitudes, social influences, social modelling and self-efficacy of women without history of breast cancer and breast cancer survivors

When a comparison is made between the comments on attitude, social influences, social modelling and self-efficacy of both samples, some rough distinctions can be made (Table 2). Concerning the attitudes, perceived advantages and disadvantages of using an eHealth programme were similar, but the comments made by breast cancer survivors were more specific than those of women without history mentioned. Differences between the two 
groups were that women without history of breast cancer cared more about abandoning cherished habits, while breast cancer survivors saw an eHealth programme as another obligation in an already busy life. Additionally, the accessibility of the programme for women without history of breast cancer was difficult. The social influences were similar for both groups, aside from the fact that breast cancer survivors expected discouragement less often. Regarding the presence of a social model, breast cancer survivors said to have a social model less frequently than women without history of breast cancer. In both samples social models were mostly perceived positively. Regarding self-efficacy, the number and diversity of expected problems were higher in women without history of breast cancer. Named enabling factors were roughly comparable between both groups. However, women without history of breast cancer expected more than just a lifestyle programme, while breast cancer survivors were very specific on the layout of an eHealth programme. When disabling factors were compared, paying much attention to breast cancer and a difficult layout of an eHealth programme were found to decrease the sense of ability to conduct lifestyle changes in both groups. In addition, breast cancer survivors mentioned a busy schedule to lower their self-efficacy.

Table 1. Summary of the characteristics of women without history of breast cancer and breast cancer survivors.

\begin{tabular}{|c|c|c|c|}
\hline \multicolumn{2}{|l|}{ Characteristics } & $\begin{array}{l}\text { Women without } \\
\text { history of breast } \\
\text { cancer }(n=10)\end{array}$ & $\begin{array}{l}\text { Breast cancer } \\
\text { survivors }(n=10)\end{array}$ \\
\hline \multicolumn{2}{|l|}{ Mean age (years) } & 42.6 & 50,3 \\
\hline \multirow{3}{*}{ Education level (n) } & High & 5 & 5 \\
\hline & Middle & 4 & 5 \\
\hline & Low & 1 & 0 \\
\hline \multicolumn{2}{|c|}{ Previous experience with breast cancer prevention counselling (n) } & 1 & 0 \\
\hline \multicolumn{2}{|l|}{ Familiarity with eHealth (n) } & 3 & 1 \\
\hline \multirow{3}{*}{ Current lifestyle (n) } & Healthy & 3 & 5 \\
\hline & Suboptimal & 6 & 5 \\
\hline & Unhealthy & 1 & 0 \\
\hline \multirow{3}{*}{ Awareness (n) } & Fully aware & 0 & 1 \\
\hline & Partly aware & 1 & 5 \\
\hline & Unaware & 9 & 4 \\
\hline
\end{tabular}




\section{Discussion/Conclusion}

The study revealed that the majority of women of both samples was unaware of the relationship between lifestyle factors and breast cancer and had rarely had breast cancer prevention counselling.

\section{Attitudes}

For women without history of breast cancer, the main advantage of an eHealth programme was enhancing awareness. Discomfort with the topic of breast cancer and having to abandon cherished habits were the main disadvantages and these findings seem to contradict each other. Literature suggests that inexperience with the disease decreases the likelihood of the execution of preventive behaviour (14). In addition, a lack of awareness of the relationship between lifestyle factors and breast cancer gives women little reason to attempt lifestyle changes $(15,16)$. Moreover, accessing the eHealth programme could be problematic for the general population.

The sample of breast cancer survivors valued the ability to ask questions. Breast cancer survivors expressed feelings of anxiety due to breast cancer-related discomfort and the reluctance to bother doctors. Literature confirms that access to information improves the quality of life of breast cancer survivors and will likely improve the psychosocial status of these women $(17,18)$. Survivors also made mention of eHealth being another obligation in an already busy life. It has yet to be determined if online lifestyle counselling will be prioritised over other daily tasks.

\section{Social influences and social modelling}

The majority of women without history of breast cancer expected social support and indicated that support would increase the motivation to make lifestyle changes. Women expecting discouragement expected a decreased motivational state. The expected influence of support and discouragement on the motivation was in agreement with the literature $(19,20)$. Furthermore, a lack of positively perceived social models might denigrate the intentions of women without history of breast cancer to make lifestyle changes (12).

Amongst breast cancer survivors, both support and discouragement influenced the motivational state less often as compared to women without history of breast cancer, possibly because an elevated level of intrinsic motivation. If that is indeed the case, it would increase the likelihood of breast cancer survivors to achieve lifestyle changes (21). 
Table 2. Comparison between the mentioned subthemes of attitude, social influences, social modelling and self-efficacy of both samples.

\begin{tabular}{|c|c|c|c|}
\hline Category & Main themes & $\begin{array}{l}\text { Subthemes: women without history } \\
\text { of breast cancer }\end{array}$ & Subthemes: breast cancer survivors \\
\hline \multirow{4}{*}{ Attitudes } & $\begin{array}{l}\text { Personal } \\
\text { advantages }\end{array}$ & $\begin{array}{l}\text { Raising awareness, working on breast } \\
\text { cancer prevention, practicality of } \\
\text { eHealth programme }\end{array}$ & $\begin{array}{l}\text { Decreasing risk of breast cancer } \\
\text { recurrence, raising awareness, being } \\
\text { able to ask questions }\end{array}$ \\
\hline & $\begin{array}{l}\text { eHealth-related } \\
\text { advantages }\end{array}$ & Personal lifestyle advice, tailoring & $\begin{array}{l}\text { Personal lifestyle advice, information } \\
\text { on specific foods, presence of a } \\
\text { question module, tailoring, not having } \\
\text { to deal with fellow-sufferers }\end{array}$ \\
\hline & $\begin{array}{l}\text { Personal } \\
\text { disadvantages }\end{array}$ & $\begin{array}{l}\text { Discomfort with the topic of breast } \\
\text { cancer, abandoning cherished habits }\end{array}$ & $\begin{array}{l}\text { Paying attention to breast cancer, busy } \\
\text { schedule }\end{array}$ \\
\hline & $\begin{array}{l}\text { eHealth-related } \\
\text { disadvantages }\end{array}$ & $\begin{array}{l}\text { Computer programme, difficulty } \\
\text { accessing the programme }\end{array}$ & Computer programme \\
\hline \multirow{3}{*}{$\begin{array}{l}\text { Social } \\
\text { influences }\end{array}$} & \multirow{3}{*}{$\mathrm{n} / \mathrm{a}$} & Support $(n=8)$ & Support $(n=7)$ \\
\hline & & Discouragement $(n=3)$ & Discouragement $(n=1)$ \\
\hline & & Indifference $(n=2)$ & Indifference $(n=3)$ \\
\hline \multirow{3}{*}{$\begin{array}{l}\text { Social } \\
\text { Modelling }\end{array}$} & \multirow{3}{*}{$\mathrm{n} / \mathrm{a}$} & No $(n=4)$ & No $(n=7)$ \\
\hline & & Yes: perceived positively $(n=4)$ & Yes: perceived positively $(n=2)$ \\
\hline & & Yes: perceived negatively $(n=1)$ & Yes: perceived negatively $(n=1)$ \\
\hline \multirow{8}{*}{$\begin{array}{l}\text { Self- } \\
\text { efficacy }\end{array}$} & $\begin{array}{l}\text { Personal } \\
\text { expected } \\
\text { problems }\end{array}$ & Abandoning cherished habits & Fading interest \\
\hline & $\begin{array}{l}\text { eHealth-related } \\
\text { expected } \\
\text { problems }\end{array}$ & Layout, lack of guidance & Computer programme \\
\hline & $\begin{array}{l}\text { Environment- } \\
\text { related } \\
\text { expected } \\
\text { problems }\end{array}$ & Busy schedule & $\mathrm{n} / \mathrm{a}$ \\
\hline & $\begin{array}{l}\text { Personal } \\
\text { enabling factors }\end{array}$ & $\begin{array}{l}\text { Making small adjustments, practical } \\
\text { advices }\end{array}$ & Practicality of eHealth programme \\
\hline & $\begin{array}{l}\text { eHealth-related } \\
\text { enabling factors }\end{array}$ & $\begin{array}{l}\text { An app, human interactivity, in-depth } \\
\text { information, a broader eHealth } \\
\text { programme, personal lifestyle advice, } \\
\text { accessible layout }\end{array}$ & $\begin{array}{l}\text { Involvement of other people, well- } \\
\text { arranged website, clarity, tailoring, } \\
\text { approaches to achieving lifestyle } \\
\text { changes }\end{array}$ \\
\hline & $\begin{array}{l}\text { Personal } \\
\text { disabling } \\
\text { factors }\end{array}$ & $\begin{array}{l}\text { Discomfort with the topic of breast } \\
\text { cancer, lack of discipline }\end{array}$ & $\begin{array}{l}\text { Antipathy of confrontation with } \\
\text { fellow-sufferers, mental lows }\end{array}$ \\
\hline & $\begin{array}{l}\text { eHealth-related } \\
\text { disabling } \\
\text { factors }\end{array}$ & $\begin{array}{l}\text { Large amounts of text, problematic } \\
\text { navigation, lack of interactivity }\end{array}$ & Timing, complicated layout \\
\hline & $\begin{array}{l}\text { Environment- } \\
\text { related } \\
\text { disabling } \\
\text { factors }\end{array}$ & $\mathrm{n} / \mathrm{a}$ & Busy schedules \\
\hline
\end{tabular}




\section{Self-efficacy}

Women without history of breast cancer expected problems in self-efficacy more often than breast cancer survivors did. This means that the belief of the ability to exert behavioural changes was lower amongst the first sample, which decreases the likelihood of achieving behavioural changes amongst women without history of breast cancer (15).

Concerning enabling factors, women without history of breast cancer indicated that an app for mobile devices would increase self-efficacy. Research concludes that few of the currently available apps on the App Store or Google Play contain all building blocks of the behavioural change theories $(22,23)$. However, this leaves room for improvement and does not imply that an app could not be designed based on evidence regarding durable behavioural change. In breast cancer survivors, general involvement of other people would increase their self-efficacy for they would feel better understood and more encouraged. Since one's intention to conduct a behavioural change is partly determined by the opinions of close referents or social models, it might be effective to indeed involve third parties $(12,19,20)$.

Finally, most mentioned disabling factors amongst both samples comprised the layout of an eHealth programme. Large amounts of text and a problematic navigation would diminish the clarity of a website and increase the time spent on the programme.

\section{Conclusions}

In the future, implementing an eHealth counselling programme in the follow-up care of breast cancer survivors seems feasible. The obtained data confirms the role of attitudes, social influences and self-efficacy in the conductance of behavioural changes. Therefore, it is recommended that the framework of the iChange Model should be integrated in possible future eHealth interventions. However, more research needs to be done in order to determine when such a programme should be introduced and whether or not eHealth counselling would be effective in realising durable lifestyle changes.

\section{Role of the student}

Simone Doreleijers was an undergraduate student who worked under the supervision of prof. dr. Hein de Vries whilst the research was conducted. The student was involved in the application for ethics approval of the medical ethics committee of the Academic hospital Maastricht and Maastricht University. Furthermore, the student designed the question routes of the interviews, conducted the interviews and processed them into transcripts 
afterwards. She analyzed the data using Nvivo and formulated the conclusions and the writing of the thesis.

\section{References}

1. Youlden DR, Cramb SM, Dunn NA, Muller JM, Pyke CM, Baade PD. The descriptive epidemiology of female breast cancer: an international comparison of screening, incidence, survival and mortality. Cancer epidemiology. 2012;36(3):237-48

2. Demark-Wahnefried W, Platz EA, Ligibel JA, Blair CK, Courneya KS, Meyerhardt JA, et al. The role of obesity in cancer survival and recurrence. Cancer Epidemiology Biomarkers \& Prevention. 2012;21(8):1244-59.

3. Holm M, Olsen A, Christensen J, Kroman NT, Bidstrup PE, Johansen C, et al. Pre diagnostic alcohol consumption and breast cancer recurrence and mortality: Results from a prospective cohort with a wide range of variation in alcohol intake. International Journal of Cancer. 2013;132(3):686-94.

4. Sanchis-Gomar F, Lucia A, Yvert T, Ruiz-Casado A, Pareja-Galeano H, Santos-Lozano A, et al. Physical Inactivity And Low Fitness Deserve More Attention To Alter Cancer Risk And Prognosis. Cancer Prevention Research. 2014:canprevres. 0320.2014.

5. Ligibel J. Lifestyle factors in cancer survivorship. Journal of Clinical Oncology. 2012;30(30):3697-704

6. Kwan ML, Kushi LH, Weltzien E, Tam EK, Castillo A, Sweeney C, et al. Alcohol consumption and breast cancer recurrence and survival among women with early-stage breast cancer: the life after cancer epidemiology study. Journal of clinical Oncology. 2010;28(29):4410-6.

7. Zhao G, Li C, Okoro CA, Li J, Wen XJ, White A, et al. Trends in modifiable lifestyle-related risk factors following diagnosis in breast cancer survivors. Journal of Cancer Survivorship. 2013;7(4):563-9.

8. Ollberding NJ, Maskarinec G, Wilkens LR, Henderson BE, Kolonel LN. Comparison of modifiable health behaviours between persons with and without cancer: the Multiethnic Cohort. Public health nutrition. 2011;14(10):1796-804.

9. Marcus BH, Lewis BA, Williams DM, Dunsiger S, Jakicic JM, Whiteley JA, et al. A comparison of Internet and print-based physical activity interventions. Archives of Internal Medicine. 2007;167(9):944-9.

10. Samoocha D, Bruinvels DJ, Elbers NA, Anema JR, van der Beek AJ. Effectiveness of web-based interventions on patient empowerment: a systematic review and meta-analysis. Journal of medical Internet research. 2010;12(2).

11. Lu H-Y, Shaw BR, Gustafson DH. Online health consultation: Examining uses of an interactive cancer communication tool by low-income women with breast cancer. International journal of medical informatics. 2011;80(7):518-28

12. I-change Model: Maastricht University; 2013 [cited 2015 15-6-2015]. Available from: http://www. maastricht-university.eu/hein.devries/interests/i-change-model.

13. de Vries H, Mesters I, Van de Steeg H, Honing C. The general public's information needs and perceptions regarding hereditary cancer: an application of the Integrated Change Model. Patient education and counseling. 2005;56(2):154-65. 
14. Schüz B, Wurm S, Warner LM, Wolff JK, Schwarzer R. Health motives and health behaviour self-regulation in older adults. Journal of behavioral medicine. 2014;37(3):491-500.

15. Bandura A. Health promotion by social cognitive means. Health education \& behavior. 2004;31(2):143-64.

16. Mann T, de Ridder D, Fujita K. Self-regulation of health behavior: social psychological approaches to goal setting and goal striving. Health Psychology. 2013;32(5):487.

17. Rutten LJF, Agunwamba AA, Wilson P, Chawla N, Vieux S, Blanch-Hartigan D, et al. Cancer-Related Information Seeking Among Cancer Survivors: Trends Over a Decade (2003-2013). Journal of Cancer Education. 2015:1-10.

18. Arora NK, Johnson P, Gustafson DH, McTavish F, Hawkins RP, Pingree S. Barriers to information access, perceived health competence, and psychosocial health outcomes: test of a mediation model in a breast cancer sample. Patient education and counseling. 2002;47(1):37-46.

19. Ajzen I. The theory of planned behavior. Organizational behavior and human decision processes. 1991;50(2):179-211.

20. Madden TJ, Ellen PS, Ajzen I. A comparison of the theory of planned behavior and the theory of reasoned action. Personality and social psychology Bulletin. 1992;18(1):3-9.

21. Thøgersen-Ntoumani $\mathrm{C}$, Ntoumanis $\mathrm{N}$. The role of self-determined motivation in the understanding of exercise-related behaviours, cognitions and physical self-evaluations. Journal of sports sciences. 2006;24(4):393-404.

21. Middelweerd A, Mollee JS, van der Wal C, Brug J, Te Velde SJ. Apps to promote physical activity among adults: a review and content analysis. Int J Behav Nutr Phys Act. 2014;11(1):97.

22. Breton ER, Fuemmeler BF, Abroms LC. Weight loss-there is an app for that! But does it adhere to evidence-informed practices? Translational behavioral medicine. 2011;1(4):523-9. 